\title{
Ensino Médio e educação profissionalizante em enfermagem: algumas reflexões
}

\author{
HIGH SCHOOLAND PROFESSIONAL EDUCATION IN NURSING: SOME REFLECTIONS
}

BACHILLERATO Y EDUCACIÓN PROFESIONAL EN ENFERMERÍA: ALGUNAS REFLEXIONES

\author{
Maria Helena Salgado Bagnato', Greicelene Aparecida Hespanhol Bassinello², \\ Cristiane Pessoa da Cunha Lacaz ${ }^{3}$, Lourdes Missio ${ }^{4}$
}

\section{RESUMO}

Este trabalho tem o objetivo de analisar as políticas de educação profissional, problematizando aspectos das mudanças efetuadas no ensino médio no Brasil. De maneira geral, as legislações aprovadas manifestam interesses das políticas neoliberais, dos organismos multilaterais e as implicações da reorganização mundial produtiva e da redução da participação do Estado nas políticas sociais. Explicita-se também a maneira de o país se articular ao processo de globalização mundial, num papel dependente, mais consumidor do que produtor de conhecimentos, perdendo a oportunidade de conquista de sua autonomia, inclusive no campo de formação profissional. Com base nas possibilidades aventadas, por essas legislações, para a organização curricular, defendemos que o ensino profissionalizante em enfermagem deve assumir uma perspectiva técnica integrada a uma educação geral, oferecida num mesmo espaço, diminuindo o risco de uma formação minimalista e aligeirada.

\section{DESCRITORES}

Educação profissionalizante. Educação técnica em enfermagem. Políticas públicas.

\begin{abstract}
Analyzing the politics of professional education and questioning the changes that have been introduced in the Brazilian high school system are the main objectives of this study. In general, the approved legislation expresses the interests of the neo-liberal policies, of multilateral organisms, and of the implications of the worldwide productive reorganization and of the reduction of State participation in social policies. It also mirrors the manner in which Brazil inserts itself in the globalization process, in a dependent role, more as a knowledge consumer than a producer of it, thus missing the opportunity for achieving its autonomy, including in the area of professional formation. Based on the possibilities that these laws offer for curricular organization, this article defends that professional teaching in Nursing should take up a technical perspective integrated to a general education and be provided in a single space, thus reducing the risk of a minimalist, superficial training.
\end{abstract}

\section{KEY WORDS}

Education, professional.

Education, nursing, associate. Public policies.

\section{RESUMEN}

Este trabajo tiene el objetivo de analizar las políticas de educación profesional, aspectos problemáticos de cambios efectuados en el bachillerato en Brasil. De modo general, las legislaciones aprobadas manifiestan, interés de las políticas neoliberales, de los organismos multilaterales e implicaciones de la reorganización mundial productiva y de la reducción de la participación del Estado en las políticas sociales. También se explica el modo que el país se articula al proceso de globalización mundial, en un papel dependiente, más consumidor que productor de conocimientos, perdiendo la oportunidad de conquistar su autonomía incluso en el campo de formación profesional. A partir de las posibilidades mencionadas, por estas legislaciones, para la organización curricular, defendemos que la enseñanza profesional en enfermería tiene que asumir una perspectiva técnica integrada a una educación general, ofrecida en el mismo espacio, disminuyendo el riesgo de una formación minimalista y aligerada.

\section{DESCRIPTORES}

Educación profesional. Graduación en auxiliar de enfermería.

Políticas públicas.

\footnotetext{
1 Enfermeira. Professora Doutora da Faculdade de Educação da UNICAMP. Pósdoutorado em Educação/ Universidade de Barcelona. Coordenadora do Laboratório de Estudos e Pesquisas em Práticas de Educação e SaúdePRAESA/UNICAMP. mbagnato@unicamp.br

2 Enfermeira Professora da Educacional Anhanguera-FAC Limeira. Doutoranda da Faculdade de Educação/PRAESA/ UNICAMP

jlabas @ terra.com.br

3 Enfermeira Professora da EEAN/ UFRJ. Doutoranda da Faculdade de Educação/PRAESA/ UNICAMP cristianelacaz@ uol.com.br 4 Enfermeira Professora da UEMS. Doutoranda da Faculdade de Educação/PRAESA/ UNICAMP. lourdesmissio@ terra.com.br
} 


\section{INTRODUÇÃO}

A última década foi bastante profícua em mudanças na legislação da educação brasileira, voltada para os diferentes níveis de ensino. Este texto, tem como objetivo analisar as políticas vigentes do ensino profissionalizante, articulando elementos presentes nas propostas legislativas com o contexto sócio, político e econômico e as implicações para o ensino profissionalizante de enfermagem.

Para isto, nos apoiaremos nas propostas da Lei de Diretrizes e Bases da Educação Nacional (LDB) n. ${ }^{\circ}$ 9.394/96, no Projeto de Lei n. ${ }^{\circ}$ 1.603/96 para a reforma do Ensino Técnico e Profissional, no Decreto n 2.208/97, na Resolução da Câmara de Educação Básica do Conselho Nacional de Educação n. ${ }^{\circ}$ 3/98 e n. ${ }^{\circ}$ 4/99 e no Decreto n. ${ }^{\circ}$ 5.154/2004. Interessanos explicitar a lógica e os interesses que estão presentes nestas reformulações que vão para além do que os documentos expressam; para isto é importante contextualizar essa legislação historicamente considerando o processo de globalização que tem afetado, embora em níveis e intensidade diferenciados, todos os países, e que traz novas formas de relação da educação com o mundo do trabalho.

É importante ressaltarmos que o ensino médio, em que o técnico se situa, tem sido historicamente, um dos níveis de mais difícil enfrentamento no que diz respeito à sua concepção, estrutura e organização, por conta da sua natureza de mediação entre a educação fundamental e a formação profissional. Não fica, portanto, clara a sua identidade. Traz uma proposta pedagógica ambígua, que nem sempre atende as finalidades de aprofundamento dos conhecimentos adquiridos no ensino fundamental como a preparação para o trabalho e para a cidadania. Passa a ser também uma questão política, pois sofre as influências das mudanças materiais de produção de cada período histórico, que acabam por redefinir a função do sistema educativo nas perspectivas econômica, social e ideológica ${ }^{(1)}$.

O processo de globalização que vivenciamos traz uma realidade bastante complexa que tem se revelado principalmente na sua faceta negativa, expressa por relações sociais bastante excludentes, globalizando particularmente o capital financeiro especulativo. Este se movimenta para diferentes locais, conforme interesses de poucos grupos detentores do poder econômico, monopolizando também o conhecimento, a ciência e as novas tecnologias de áreas estratégicas, trazendo consequiências para as formas de organização e o acesso ao trabalho, bem como novas exigências para a qualificação dos trabalhadores ${ }^{(2)}$.

Assim, a globalização tem criado grandes dificuldades econômicas, alargando a distância entre países ricos e po- bres, não significando uma maior equalização nas sociedades, como muitas vezes a ideologia dominante, neoliberal, nos quer fazer crer.

As transformações que ocorrem nos setores produtivos e de serviços articuladas à globalização da economia influenciam também a formação profissional, requerendo novas qualificações dos trabalhadores.

Nessas discussões, é importante considerar também a participação de organismos internacionais nas proposições gerais das políticas educacionais do país, que se faz presente através de alguns eixos como o princípio da eqüidade, em substituição ao da igualdade através de estratégias de desregulamentação, descentralização, autonomia e privatização.

\section{TRAMITAÇÃO DA LEGISLAÇÃO}

Este contexto geral nos ajuda a compreender movimentos de resistência do Executivo e das forças políticas e econômicas conservadoras ao projeto da LDB, que tramitava na Câmara dos Deputados, cujo texto inicial foi elaborado e deu entrada neste espaço em 1988, contando com uma ampla participação e discussão da comunidade acadêmica e de outros setores sociais, recebendo nestas movimentações várias versões, inúmeras sugestões formais ou informais e alguns substitutivos.

Este projeto, com características mais progressistas, teve um longo período de embate em que interesses diversos (tanto orçamentários quanto de instituições públicas e privadas) foram se manifestando e, surpreendentemente, outro projeto vindo do Senado com sucessivas versões, ganha espaço, resultando no texto final da nova LDB da Educação Nacional, trazendo uma proposta com aspectos conservadores da educação, expressando os interesses da política governamental e as recomendações de organismos internacionais, atendendo aos imperativos neoliberais nesta área, a saber: "valorização dos mecanismos de mercado, apelo à iniciativa privada e às organizações não-governamentais em detrimento do lugar e do papel do Estado e das iniciativas do setor público, com a conseqüente redução das ações e dos investimentos públicos"(3).

O Projeto de Lei que resulta na LDB n. ${ }^{\circ}$ 9.394, de 1996, se diferencia da primeira proposta apresentada, tanto em termos do processo de elaboração quanto ao conteúdo, com a União assumindo o papel de complementação dos recursos para o ensino fundamental, quando os Estados e os Municípios não derem conta comprovadamente destes gastos; também cabe ao Estado oferecer com prioridade, o ensino médio. 
A formação técnico-profissional, a que nos deteremos neste texto, não aparece no capítulo do ensino médio, mas no capítulo VII, através de dois artigos e três parágrafos, com a seguinte redação:

“Art.39 - A educação profissional, integrada às diferentes formas de educação, ao trabalho, à ciência e à tecnologia, conduz ao permanente desenvolvimento de aptidões para a vida produtiva.

Parágrafo único - O aluno matriculado ou egresso do ensino fundamental, médio e superior, bem como o trabalhador em geral, jovem ou adulto, contará com a possibilidade de acesso à formação profissional.

Art. 40 - A educação profissional será desenvolvida em articulação com o ensino regular ou por diferentes estratégias de educação continuada, em instituições especializadas ou no ambiente de trabalho.

Art. 41 - O conhecimento adquirido na educação profissional, inclusive no trabalho, poderá ser objeto de avaliação, reconhecimento e certificação para prosseguimento ou conclusão de estudos.

Parágrafo único - Os diplomas de cursos de educação profissional de nível médio, quando registrados, terão validade nacional.

Art. 42 - As escolas técnicas e profissionais, além de seus cursos regulares, oferecerão cursos especiais, abertos à comunidade, condicionada a matrícula à capacidade de aproveitamento e não necessariamente ao nível de escolaridade" $(4)$.

Podemos verificar que esse capítulo não explicita instâncias, competências e responsabilidades em relação à educação profissional; de quem seriam? Da União? Dos Estados? Dos Municípios? Das empresas?

O Plano Nacional de Educação (PNE) previsto pela Constituição Federal de 1988 fica postergado, não sendo explicitado na nova LDB, mas é colocado como uma prerrogativa do Executivo, bem como as diretrizes e bases da política a serem implementadas, com isso denuncia-se uma tendência centralizadora na área da educação ${ }^{(5)}$. O PNE foi aprovado em 2001, definindo os objetivos, as diretrizes e as metas para a educação brasileira até $2010^{(6)}$.

Concordamos com alguns autores ${ }^{(5)}$ quando apontam que esta LDB "não faz mais que retroceder no que tange à gestão democrática dos sistemas de educação e das instituições escolares, oficializando e ratificando prerrogativas centralizadoras e impositivas das chamadas "autoridades educacionais"

Concomitantemente à LDB, tramita neste período no Congresso Nacional, um Projeto de Lei (PL) n. ${ }^{\circ}$ 1.603/96 relativo ao ensino técnico e profissional de iniciativa do Gover- no Federal, com a pretensão de constituir um Sistema Nacional de Educação Tecnológica. Este processo envolveu discussões de dois grupos ligados à Secretaria de Educação Média e Tecnológica (SEMTEC) do MEC e à Secretaria de Formação e Desenvolvimento Profissional (SEFOR) do Ministério do Trabalho, apresentando concepções de formação profissional diferenciadas.

O grupo da SEFOR fez interlocuções com outros setores e considerou em suas discussões, a educação brasileira como um todo, apresentando os aspectos críticos da educação do trabalhador, diante das novas exigências do processo produtivo, de uma maior competitividade internacional, da melhoria das condições de vida do povo brasileiro e as implicações disto para a educação profissional. O texto produzido por este grupo trazia uma reflexão sobre as questões colocadas pela nova etapa do desenvolvimento das forças produtivas, mas buscava alternativas para uma relação harmoniosa dos resultados da ação educativa com as atuais necessidades da realidade brasileira, voltando-se não só para as demandas do mercado nacional e internacional, mas também para a consolidação do processo democrático no que concerne à formação do cidadão produtivo, buscando redefinir o conceito de trabalho e qualificação, considerando como clientela os desempregados e excluídos. Aponta o FAT (Fundo de Apoio ao Trabalhador) como uma das fontes de financiamento e o MEC como responsável pelo Sistema Nacional de Educação ${ }^{(1)}$.

Desta forma, o PL n. ${ }^{\circ} 1.603 / 96$ contou com as discussões que se deram por este grupo da SEFOR, e do outro tem origem na SEMTEC do MEC, que trazia uma discussão a partir de avaliações feitas por consultores do Banco Mundial e de instituições públicas nacionais, que expressam preocupações com o aumento de recursos financeiros neste nível de ensino e o aumento da demanda e o alto custo das escolas técnicas em função dos seus resultados.

O MEC através do SEMTEC propôs-se a assumir o processo de redefinição do ensino médio, separando formação acadêmica da profissional do ponto de vista conceitual e operacional, utilizando um modelo flexível para os currículos possibilitando uma maior adaptação dos mesmos ao mercado de trabalho, tendo como preocupação também a diminuição dos seus custos.

Desta forma, o PL n. ${ }^{\circ}$ 1.603/96, através da maneira com que foi se configurando, acabou atendendo a uma política neoliberal presente no país, articulada ao movimento de globalização da economia, que traz exigências de racionalização do uso de recursos e diminuição da presença do Estado nas políticas sociais, pretendendo também atender o aumento da flexibilidade, qualidade e produtividade no sistema produtivo ${ }^{(1)}$.

Esse Projeto ao tramitar no Congresso sofreu uma disputa entre diferentes interesses de educadores ligados ao 
ensino técnico que buscavam uma concepção de educação técnica unitária, tecnológica e de caráter público e os interesses do governo. Com a aprovação da LDB este PL foi retirado pelo executivo que o transformou no Decreto n. ${ }^{\circ} 2.208 / 97$ impondo uma reforma que contempla os interesses presentes, desde o início, com um teor conservador, pronunciando o dualismo (criando um sistema profissional fora do sistema regular de ensino, o que não aparecia na LDB, padecendo, portanto, para muitos educadores de inconstitucionalidade), o tecnicismo e a fragmentação do conhecimento, trazendo a organização da formação profissional em três níveis: básico, técnico e tecnológico ${ }^{(7)}$.

No nível básico são oferecidos cursos não necessariamente regulamentados, ligados ao Ministério do Trabalho e que tem como objetivo qualificar, requalificar ou reprofissionalizar os trabalhadores independentemente da escolaridade anterior.

O nível técnico terá uma organização curricular específica e separada do ensino médio, voltado para os que estão matriculados ou os egressos do ensino médio, sendo desenvolvido através de uma estrutura modular, que considerará as habilidades básicas e específicas de conhecimentos, atitudes e de gestão de qualidade, buscando competências polivalentes em consonância com as necessidades da economia. Explicita-se e pronuncia-se claramente o caráter ideológico destas mudanças, com a distinção da dualidade estrutural de uma formação voltada exclusivamente para as necessidades do mercado, para a produtividade, inclusive desvinculada de uma política democrática e pública de desenvolvimento e geração de empregos, num momento que boa parte dos trabalhadores estão sendo excluídos deste direito.

O nível tecnológico, por sua vez, é destinado para os egressos do ensino médio e técnico, voltado para diferentes especialidades.

Dessa forma, o Decreto n..$^{\circ}$ 2.208/97 objetivou elucidar a estrutura e o funcionamento do ensino profissionalizante em nosso país. É o documento que melhor explicita as intenções deste novo contexto educacional a partir da regulamentação dos artigos 39 a 42 da LDB e do $\S 2^{\circ}$ do artigo 36, que sinaliza atendimento às necessidades do mercado. É possível ver nesta proposta uma orientação pedagógica da competitividade, centrada nos conceitos de competências e habilidades, e que tem como interlocutor intelectual prioritário o Banco Mundial, que persegue como diretriz geral a adaptação e conformação do trabalhador no plano físico, psíquico, intelectual e emocional às novas bases materiais, tecnológicas e organizacionais da produção(2).
Em 1998, o Conselho Nacional de Educação instituiu as Diretrizes Curriculares Nacionais para o Ensino Médio através da Resolução CEB n. ${ }^{\circ}$ 3/98, estabelecendo princípios, fundamentos e procedimentos para este nível de ensino, articulando a educação com o mundo do trabalho e a prática social. De maneira geral, esta Resolução reitera as intenções explicitadas anteriormente para o ensino médio ${ }^{(8)}$.

Nesta Resolução são adotados três princípios gerais para os procedimentos relacionados às práticas administrativas, organizativas e pedagógicas nos sistemas de ensino e nas formulações e implementação de políticas educacionais: a Estética da Sensibilidade, a Política da Igualdade e a Ética da Identidade, mostrando uma redundância de termos, pois desconsidera que a sensibilidade está presente na estética, e dá preferência para o uso do conceito igualdade ao invés de equidade, o que pressupõe perpetuar diferenças na medida que se pretende um tratamento igual para quem tem condições diferentes.

Considera também Identidade, Diversidade, Autonomia, Interdisciplinaridade e Contextualização como princípios pedagógicos estruturadores dos currículos do ensino médio. A questão curricular da educação profissionalizante orientou-se pela Resolução CEB n. ${ }^{\circ} 04 / 99^{(9)}$ juntamente com o Parecer CEB n. ${ }^{\circ} 16 / 99^{(10)}$. A resolução aponta para os princípios norteadores da educação profissional de nível médio, destacando a independência e a articulação com este nível, desenvolvimento de competências para a laboralidade, autonomia da escola em seu projeto pedagógico, atualização permanente dos cursos e currículos e identidade dos perfis profissionais de conclusão de curso. Os critérios para a organização e o planejamento dos cursos, segundo o artigo $4^{\circ}$ da Resolução CEB n..$^{\circ}$ 04/99, atendem as demandas dos cidadãos, do mercado e da sociedade conciliadas com as demandas identificadas, com a vocação e a capacidade institucional da escola ou da rede de ensino.

A exigência da Resolução é o desenvolvimento de competências profissionais para a formação do trabalhador delimitando as diferentes áreas de atuação profissional e cargas horárias mínimas para cada área. A referencia básica para a organização do curso é a área profissional que compreende as competências profissionais gerais, comuns a todos os técnicos da área e que se unem às competências específicas para cada curso a serem definidas pela escola em função do perfil de conclusão.

Essas reformulações atendem principalmente a interesses, já explicitados, deixando de lado questões imprescindíveis de se refletir na formação profissional, como por exemplo: "Como articular teoria e prática na formação do traba- 
lhador, diante da formação demandada e da agilidade com que deva ser produzida? A quem deve dirigir-se prioritariamente a formação profissional? Ao setor moderno, às pequenas e médias empresas, ao setor desestruturado da economia? Que público privilegiar? Quem pode ser identificado como agência de formação profissional nesse sentido?"(11) Estas e muitas outras questões podem ser formuladas, situando-as no momento atual em que também o Brasil passa por uma grave crise de emprego, portanto num mercado instável, que se por um lado exige atualização e novas qualificações dos trabalhadores para dar conta de novos conhecimentos e novas tecnologias, por outro lado, também, o modelo econômico implementado traz outras formas de organização dos setores, excluindo muitos postos de trabalho, gerando conflitos sociais e pronunciando a pobreza.

Neste contexto, o compromisso dos educadores é buscar e organizar uma formação profissional que considere as necessidades do trabalhador e não somente as perspectivas do mercado. Isso implica enfrentamento das contradições e dos desafios presentes neste momento histórico, não como uma situação determinada, mas condicionada e, portanto, com possibilidades de transformações, ensejando uma formação politécnica preocupada com a construção do homem omnilateral (sujeito de direitos e deveres, construtor de sua história, inserido no mundo do trabalho, dotado de consciência crítica que lhe possibilite autonomia e não simplesmente subserviência ao se relacionar com o mundo), centrada numa unidade orgânica entre educação, trabalho e conhecimento, buscando uma formação que desenvolva as múltiplas dimensões do ser humano, condição fundamental para a cidadania efetiva e para a compreensão das mudanças na sociedade.

Em 2004, o Decreto n. ${ }^{\circ}$ 2.208/97 foi revogado, sendo substituído pelo Decreto n. ${ }^{\circ}$ 5.154, de 23 de julho de 2004. Este novo decreto não introduz mudanças significativas na estrutura do ensino profissionalizante perpetuando a mesma lógica e princípios de organização por áreas profissionais e articulação das áreas de educação, trabalho e emprego, ciência e tecnologia, dando continuidade a proposta do itinerário formativo que objetiva a qualificação para o trabalho e a elevação do nível de escolaridade do trabalhador. Este novo decreto prevê apenas a inclusão de outra possibilidade do desenvolvimento da educação profissional que pode ocorrer de forma integrada com o ensino médio além das formas concomitante e seqüencial previstas no decreto anterior ${ }^{(12)}$.

\section{O ENSINO PROFISSIONALIZANTE EM ENFERMAGEM}

Até o início das mudanças explicitadas neste texto, a organização dos cursos nesta área obedecia a Lei n. ${ }^{\circ}$ 5.692, de 11 de agosto de 1971. Os cursos de auxiliar e técnico em enfermagem, através desta lei, de uma regulamentação es- pecífica passaram a integrar o sistema educacional do país em nível de $2^{\circ}$ grau (hoje ensino médio) e podiam ser oferecidos como cursos regulares: organizados como currículo integrado (educação geral mais educação profissional) ou como supletivo (composto somente de matérias profissionalizantes).

A partir de 1996, a LDB, no capítulo dedicado à educação profissional, trouxe repercussões importantes para a estrutura dos cursos profissionalizantes de enfermagem, entre elas, a separação da educação profissional do ensino médio. O Decreto n. ${ }^{\circ}$ 2.208/97 possibilitou que os cursos tivessem organização própria e independente do ensino médio. Este novo itinerário de profissionalização permitiu que os cursos pudessem ser oferecidos de maneira "flexível", ou seja, em módulos complementares e seqüenciais, com caráter de terminalidade para efeito de qualificação profissional. Desta forma, os cursos de auxiliar de enfermagem são operacionalizados em nível de ensino fundamental, isto é, após a conclusão deste; os de técnico, em nível de ensino médio ministrado concomitante ou posterior a este nível de ensino.

Nesta perspectiva, não existe mais a separação entre cursos regulares e supletivos para o ensino profissionalizante em enfermagem, para a qualificação profissional de auxiliar de enfermagem, denominado como auxiliar técnico, ou seja, o aluno cursa o primeiro módulo obtendo certificado de auxiliar de enfermagem e no segundo módulo o diploma de técnico de enfermagem. No caso de opção pelo curso técnico há necessidade de conclusão do ensino médio ou duas matrículas diferenciadas, uma para o ensino médio e outra para o curso profissionalizante.

Uma das questões de impacto para a enfermagem, neste período, era que frente a esta legislação (Decreto n. ${ }^{\circ}$ 2.208/ 97) não exista mais a habilitação profissional de auxiliar técnico, subsistindo a do auxiliar de enfermagem. O curso de qualificação profissional de auxiliar de enfermagem integraria itinerário de profissionalização do técnico de enfermagem, sendo oferecido como um módulo do curso técnico. Esta nova condição traz obstáculos para um projeto que vinha ocorrendo em todo o território nacional, promovendo a profissionalização dos atendentes de enfermagem: o PROFAE (Projeto de Profissionalização dos Trabalhadores da Área de Enfermagem). A fim de viabilizar os cursos de auxiliar de enfermagem foi necessário outro parecer da Câmara de Educação Nacional de Educação - Parecer CEB n. ${ }^{\circ}$ 10/2000 que pudesse resolver a problemática, pois, o curso de auxiliar de enfermagem seria enquadrado como modalidade de educação não formal e não sujeito a regulamentação curricular porque estes cursos encontram-se na faixa de qualificação profissional de nível básico que não estavam sendo autorizados pelos referidos Conselhos. Este Parecer definiu com clareza a situação dos cursos de qualificação profissional que integram itinerários de profissionalização do nível técnico. O PROFAE foi considerado um projeto a ser desenvolvido em um período de transição por se tratar 
de um projeto emergencial, porém, os alunos deveriam ser estimulados a cursar o ensino médio e devidamente orientados para a continuidade dos estudos até a conclusão do técnico de enfermagem ${ }^{(13)}$.

Por sua vez, o Conselho Federal de Enfermagem - COFEN, a partir das legislações que regulamentam o ensino profissionalizante (o Decreto Federal n. ${ }^{\circ}$ 2.208/97, a Resolução CEB n. ${ }^{\circ}$ 04/99 e o Parecer CEB n. $\left.{ }^{\circ} 10 / 2000\right)$ instituiu a Resolução COFEN n. ${ }^{\circ}$ 276/2003 ${ }^{(14)}$ que concede aos auxiliares de enfermagem ingressantes na categoria somente a inscrição profissional provisória e estipula o prazo de cinco anos para que estes profissionais se habilitem como técnico de enfermagem ou prossigam seus estudos cursando a graduação, pois os cursos de auxiliar de enfermagem podem ser itinerários para habilitação do técnico de enfermagem.

É possível verificar que as reformas oficiais efetivadas na educação nem sempre foram articuladas às necessidades da categoria de enfermagem e a outros agentes do campo da legitimação profissional como a Associação Brasileira de Enfermagem (ABEn) e os Conselhos de classe.

Outro ponto a ser considerado no processo de reforma e reorganização da educação profissional em enfermagem refere-se a medidas que se contrapõem ao discurso de formar para o mercado de trabalho (no caso este mercado diz respeito principalmente a área hospitalar), inserindo este elemento como um importante eixo na orientação do itinerário de formação para a habilitação de técnico em enfermagem. No entanto, dados do mercado de trabalho em enfermagem, indicam que no ano de 2005, 57,7\% destes trabalhadores são auxiliares, representando a maior força de trabalho em todos os Estados, e que os mesmos estão inseridos no setor público, explicitando uma disposição pela contratação de mão de obra mais barata; enquanto que os técnicos, que são em menor número representam $26,0 \%$ e se concentram na área hospitalar ${ }^{(15)}$.

Por sua vez, a crise no emprego ou a caracterização de novos tipos de emprego e de vínculos, em geral mais flexíveis e precários, não tem diminuído as exigências na formação. Ao contrário, a polivalência e a ampliação de competências, fazem parte do acervo necessário, em um ambiente, cada vez mais, competitivo e excludente.

As Diretrizes Curriculares Nacionais para a Educação Profissional foram definidas pela Resolução CNE/CEB n. ${ }^{\circ}$ 04/99 e pelo Parecer CNE/CEB n. ${ }^{\circ}$ 16/99 ambas aprovadas em 05/10/99; elas organizam a educação profissional por áreas, cargas horárias e conteúdos mínimos fixados por habilidades e competências básicas, em cada área profissional. Para as habilitações na área de saúde a carga horária mínima é de 1.200 horas complementadas pelo estágio supervisionado que somam $50 \%$ da carga horária mínima. As competências profissionais gerais do técnico da área de saúde são listadas a partir da caracterização da área e as competências específicas de cada habilitação devem ser definidas pela escola para completar o currículo, em função do perfil profissional de conclusão. Para o ensino médio de enfermagem a possibilidade de diferentes modelos de organização e de autonomia das escolas em seus projetos pedagógicos faz com que as escolas tenham liberdade e autonomia para criarem novos cursos e planos de ensino baseados nestas alternativas de articulação. Em nosso entendimento, esta questão pode pronunciar um acelerado crescimento do número de escolas profissionalizantes, principalmente no setor privado, além do risco de assumir uma perspectiva minimalista e aligeirada do processo de formação.

As discussões e os embates em torno do Decreto n. ${ }^{\circ}$ 2.208/ 97, que proibia a junção entre o ensino médio e a educação profissional e seus desdobramentos para o ensino profissionalizante resultaram na possibilidade de sua substituição, mobilizando num curto período de tempo o posicionamento de várias entidades ligadas à área de educação profissional. Em 2004, o Decreto Federal n. ${ }^{\circ}$ 5.154/ 2004 substitui o Decreto n. ${ }^{\circ}$ 2.208/97, mantendo as possibilidades de formação anterior e cria uma articulação entre os dois ensinos, instituindo uma terceira opção de ensino profissionalizante em que o curso técnico poderá ser feito com o ensino médio com apenas uma matrícula em instituições com períodos integrais de aula.

Diante desta nova proposição, gostaríamos de explicitar alguns aspectos do Parecer da Associação Brasileira de Enfermagem - $\mathrm{ABEn}^{(16)}$ e o pronunciamento da Associação Nacional de Pós-Graduação em Pesquisa em Educação ANPEd representada pelo Grupo Técnico de Trabalho e Educação sobre a minuta do novo decreto que substituiria o Decreto n. ${ }^{\circ} 2.208 / 97^{(17)}$.

De acordo com este grupo (ANPEd), o Decreto n. ${ }^{\circ}$ 2.208/ 97 reitera os mecanismos de profissionalização em detrimento de uma formação geral e politécnica e, neste sentido, a revogação do Decreto representa forte simbolismo, pois este documento demonstra a maneira detalhada e explícita das intenções da educação profissionalizante contidas na LDB. Manifesta-se favorável à revogação imediata do referido Decreto, sem a substituição por um outro, o que apenas regulamentaria o que já está disposto na lei maior, ou seja, reafirmaria sua ótica profissionalizante.

Por sua vez, a ABEn, por intermédio da sua Diretoria de Educação, considera que a Minuta que revoga alguns itens do Decreto pode produzir efeitos indesejáveis sobre as formas de educação profissional, desenvolvidas enquanto estratégias para qualificar os profissionais da área de saúde, como por exemplo o PROFAE, programa que oferece cursos para a profissionalização dos auxiliares e técnicos em enfermagem nos moldes do Decreto n. ${ }^{\circ} 2.208 / 97^{(16)}$.

A nosso ver, faz-se necessário que as instituições que marcam presença na formulação de políticas educacionais colaborem para que este debate ocorra junto às entidades 
coletivas e atores participantes dos processos formativos no sentido de promover contribuições efetivas de grupos de interesses e evitar resistências de alguns segmentos e, deste modo avançar na construção de consensos a partir da análise do processo de ensino de enfermagem.

Assim, temos a mesma opinião do estudo que destaca a urgência na definição de políticas afirmativas para a educação profissional, integradas a políticas de educação básica de qualidade, assim como, políticas de geração de emprego e renda, de modo a que não se reitere a exclusão social dos trabalhadores ${ }^{(18)}$.

A partir das possibilidades aventadas por estas legislações para a organização curricular, defendemos que o ensino profissionalizante em enfermagem deve assumir uma perspectiva técnica integrada a uma educação geral, oferecida num mesmo espaço, diminuindo o risco de uma formação minimalista e aligeirada. Este momento atual requer releituras das legislações existentes no sentido de eleger estratégias e possibilidades de mudanças coerentes que contemplem as necessidades sociais, inclusive as de saúde da maioria da população.

\section{CONSIDERAÇÕES FINAIS}

A análise de alguns aspectos das mudanças ocorridas na educação profissional nos mostra a importância de um acompanhamento e avaliação constantes das políticas educacionais, historicizando suas bases, os fundamentos das formulações destas políticas, explicitando suas contradições e ambigüidades.

O modelo que tem predominado na formação profissional afasta-se da possibilidade de uma escola única, com uma sólida formação geral, politécnica, atendendo muito mais aos anseios da lógica do Banco Mundial, que passa a exigir um ajuste normativo do Brasil, partindo do princípio de que o ensino técnico desenvolvido no nosso país é muito oneroso e irracional, pois muitos alunos que cursam escolas técnicas, o fazem na perspectiva propedêutica de ingresso para o ensino superior. Nesta lógica, portanto, é dinheiro público jogado fora o que, em tempos de globalização, de racionalização de gastos sociais públicos para os países pobres, significa uma política de limitar o investimento estatal nos níveis de ensinos técnico, tecnológico e superior, abrindo espaço para iniciativa privada.

Nos últimos anos, as legislações voltadas para a área de educação no Brasil foram elaboradas topicamente, isto é,

\section{REFERÊNCIAS}

1. Kuenzer A. Ensino médio e profissional: as políticas do Estado neoliberal. São Paulo: Cortez; 1997.

2. Frigotto G. A educação e formação técnico-profissional frente à globalização excludente e o desemprego estrutural. In: Silva LH, organizadores. A escola cidadã no contexto da globalização. Petrópolis: Vozes; 1998. p. 218-38. pensadas separadamente para cada nível, porém expressando a mesma lógica, com o predomínio de uma ideologia de desregulamentação, flexibilização e privatização, elaboradas de cima para baixo, tendo como grande interlocutor o Banco Mundial (que dá as diretrizes da organização, as prioridades e os conteúdos, direcionados principalmente por uma concepção produtivista em todos os níveis de ensino).

Concordamos que, como educadores comprometidos com uma sociedade democrática e com a inclusão dos cidadãos em todos os espaços sociais, temos o compromisso de participar do embate permanente contra esta ideologia que vem se explicitando nestas propostas e colaborar na construção contra-hegemônica de um projeto que resgate as questões éticas e políticas na perspectiva de um ensino técnico unitário, politécnico, de caráter público, preocupado com uma formação humana que desenvolva as múltiplas dimensões do ser humano, com necessidades materiais, afetivas, culturais, estéticas ${ }^{(2)}$.

É um trabalho de formação reflexivo, no qual as decisões a serem tomadas implicam articulação de vários saberes que provêm de várias instâncias, tais como a formação geral, a formação profissional e as experiências de trabalho e sociais, mediados pela dimensão ético-política ${ }^{(19)}$.

A práxis educativa que se faz presente na formação profissional, inclusive na enfermagem, deveria estar contemplando estas preocupações, procurando enfrentá-las e superá-las nos diferentes espaços sociais e políticos, o que demandará que também este nível de ensino passe a ocupar um lugar de destaque nas discussões da área.

Estas legislações que trazem mudanças no ensino médio de enfermagem, assim como outras questões do ensino profissionalizante mereceriam um amplo debate das entidades de classe da área, com a participação dos profissionais que atuam neste nível de ensino e de todos envolvidos nos espaços de educação e saúde.

Acreditamos que a luta coletiva ainda pode ser um espaço bastante profícuo para defendermos um projeto de formação voltado para as necessidades de saúde da população, contemplando neste processo as múltiplas dimensões do conhecimento envolvendo questões técnico-científicas, éticas, políticas, sociais e culturais. Tarefa nada fácil, mas que deveria envolver todos educadores que participam deste trabalho.
3. Saviani D. A nova Lei da Educação: LDB, trajetória, limites e perspectivas. $4^{\mathrm{a}}$ ed. Campinas: Autores Associados; 1998.

4. Brasil. Lei n. 9.394, de 20 de dezembro de 1996. Estabelece as diretrizes e bases da educação nacional [legislação na Internet]. Brasília; 1996. [citado 2005 fev. 17]. Disponível em: http:// www.portalmec.gov.br 
5. Muranaka MAS, Minto CA. Organização da educação escolar. In: Minto CA, Muranaka MAS, Camargo RB, Paro VH. Gestão, financiamento e direito à educação. $2^{\mathrm{a}}$ ed. São Paulo: Xamã; 2001. p. 45-68.

6. Instituto Nacional de Estudos e Pesquisas Educacionais Anísio Teixeira (INEP). Os desafios do Plano Nacional de Educação. Brasília; 2004.

7. Brasil. Decreto n. 2.208, de 17 de abril de 1997. Regulamenta o $\S 2^{\circ}$ do art. 36 e o art. 39 a 42 da Lei n. ${ }^{\circ} 9.394$ de 20 de dezembro de 1996, que estabelece as Diretrizes e Bases da Educação Nacional [legislação na Internet]. Brasília; 1997. [citado 2005 fev. 17].Disponível em: http://www.portalmec.gov.br

8. Brasil. Ministério de Educação. Resolução CEB n. 3, de 26 de junho de 1998. Institui as Diretrizes Curriculares Nacionais para o Ensino Médio [legislação na Internet]. Brasília; 1998. [citado 2005 fev 17]. Disponível em: http:// www.portalmec.gov.br

9. Brasil. Ministério da Educação. Resolução CEB n. 4, de 3 de dezembro de 1999. Institui as Diretrizes Curriculares Nacionais para a Educação Profissional de Nível Técnico [legislação na Internet]. Brasília; 1999. [citado 2007 fev. 17]. Disponível em: http:// www.portalmec.gov.br

10. Brasil. Ministério da Educação. Parecer CEB n. 16/99. Diretrizes Curriculares Nacionais para a Educação Profissional de Nível Técnico [legislação na Internet]. Brasília; 1999. [citado 2005 fev. 17]. Disponível em: http:// www.portalmec.gov.br

11. Ferretti CJ. Formação profissional e reforma do ensino técnico no Brasil: anos 90. Rev Educ Soc. 1997;18(59):225-69.

12. Brasil. Decreto n. 5.154, de 23 de julho de 2004. Regulamenta o $\S 2^{\circ}$ do art. 36 e o art. 39 a 41 da Lei n. ${ }^{\circ} 9.394$, de 20 de dezembro de 1996, que estabelece as Diretrizes e Bases da Educação Nacional. Diário Oficial da União, Brasília, 26 jul. 2004. Seção 1. p. 1.

13. Brasil. Ministério da Educação. Parecer CEB n.10/2000. Providências do CNE/CEB para orientar os Conselhos Estaduais de Educação sobre procedimentos para implantar a Educação Profissional de Nível Técnico [legislação na Internet]. Brasília; 2000. [citado 2005 fev. 17]. Disponível em: http:// www.portalmec.gov.br
14. Conselho Federal de Enfermagem (COFEN). Resolução COFEN 276/2003. Regula a Concessão de Inscrição Provisória ao Auxiliar de Enfermagem [legislação na Internet]. Brasília; 2003. [citado 2005 fev. 17]. Disponível em: http:// www.portalconfen.org.br

15. Conselho Federal de Enfermagem (COFEN). Dados estatísticos [texto na Internet]. Brasília; 2006. [citado 2006 mar. 29]. Disponível em: http:// www.portalcofen.org.br

16. Associação Brasileira de Enfermagem (ABEn). Considerações sobre a regulamentação do artigo 36, os artigos 39 a 42 da Lei n. ${ }^{\circ}$ 9.304/96 e que revoga o Decreto n. ${ }^{\circ}$ 2.208/97 [texto na Internet]. Brasília; 2005. [citado 2005 fev. 17]. Disponível em: http://www.anbennacional.org.br/direducacao

17. Associação Nacional de Pós-Graduação e Pesquisa em Educação (ANPED). Grupo Técnico de Trabalho e Educação. Pronunciamento sobre a minuta do decreto que regulamenta o artigo 36 e os artigos 39 a 42 da Lei n. 9.394, de 20 de dezembro de 1996 [texto na Internet]. Brasília: SEMTEC/MEC; 2003. [citado 2005 fev. 17]. Disponível em: http://www.anped.org.br/ representaoesanped2004.pdf

18. Kuenzer AZ. As propostas de decreto para regulamentação do ensino médio e da educação profissional: uma análise crítica. In: Associação Nacional de Pós-Graduação e Pesquisa em Educação (ANPED). Grupo Técnico de Trabalho e Educação. Pronunciamento sobre a minuta do decreto que regulamenta o artigo 36 e os artigos 39 a 42 da Lei n. 9.394, de 20 de dezembro de 1996 [texto na Internet]. Brasília: SEMTEC/MEC; 2003. [citado 2005 fev. 17]. Disponível em: http://www.anped.org.br/ representaoesanped2004.pdf

19. Offe C. Trabalho e sociedade: problemas estruturais e perspectivas para o futuro da sociedade do trabalho. Rio de Janeiro: Tempo Brasileiro; 1991. 